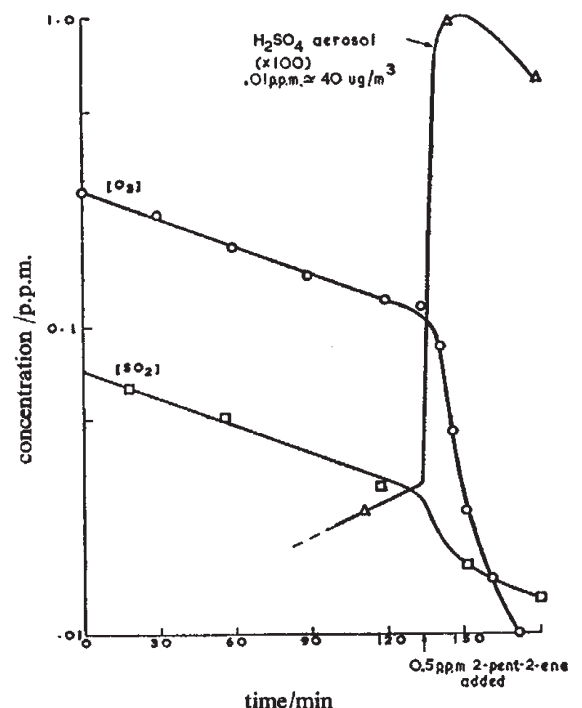

Curves of concentration against time for the reaction of ozone and $\mathrm{SO}_{2}$, showing formation of $\mathrm{H}_{2} \mathrm{SO}_{4}$ aerosol on the addition of cis-pent-2-ene. (From Cox and Penkett, J. Chem. Soc.,

Faraday Trans. I, 68, 1735; 1972.)

in the lower atmosphere than oxidation of dissolved $\mathrm{SO}_{2}$ to sulphuric acid in water droplets. This is especially true if the droplets contain certain trace metals which act as catalysts for the oxidation. The droplets with sulphuric acid in them will subsequently react rapidly with any ammonium or sodium chloride in the air to form an aerosol of sulphate particles.

Because sulphur dioxide does not react directly with olefins, and the oxidation of $\mathrm{SO}_{2}$ by ozone occurs only at a slow rate, Cox and Penkett conclude that all three components (ozone, olefin and $\mathrm{SO}_{2}$ ) are necessary for rapid formation of the sulphuric acid aerosol.

Various olefins containing between four and six carbon atoms were used in the experiments, the rate of reaction being appreciably faster for internally unsaturated olefins (those in which the double bond is not at the end of the molecule). The rate of reaction is dependent on the concentration of both ozone and olefin, which are consumed in roughly equal amounts. Cox and Penkett consider two possible mechanisms for the process, both of which have the initial reaction of ozone and olefin to form an intermediate as the rate-determining step. In one the ozone bridges across the double bond of the olefin to form a ring complex, and in the other the ozone and olefin form a zwitter (or internal) ion. Whichever intermediate is formed it speedily oxidizes the $\mathrm{SO}_{2}$ to $\mathrm{SO}_{3}$ and is itself reduced to an aldehyde. Once produced, the $\mathrm{SO}_{3}$ will rapidly react with water to form sulphuric acid, which subsequently nucleates to form the aerosol. From the laboratory experiments it seems that the rate of aerosol formation decreases with increase in relative humidity. Cox and Penkett find no obvious explanation for this result, and conclude that its elucidation must await further information about the intermediate formed in the reaction of ozone and olefin and details of the aerosol formation process.

In the final section of their article Cox and Penkett discuss the application of the $\mathrm{SO}_{2}$ oxidation rates determined in their laboratory experiments to the real atmosphere. Downward mixing of stratospheric ozone, followed by admixture with urban air containing $\mathrm{SO}_{2}$ and olefins from fossil fuel combustion, is a possible route for sulphate aerosol formation by means of the ozone-olefin reaction. But because of the rather low concentrations of ozone and olefin in this situation $(0.03$ and 0.005 p.p.m. respectively) the rate of oxidation of $\mathrm{SO}_{2}$ is only $0.1 \% \mathrm{~h}^{-1}$. In polluted air the levels of ozone may be considerably higher because of photochemical formation of the gas in situ by reaction between $\mathrm{NO}_{2}$ and hydrocarbons. In such environments ozone and olefin levels of 0.1 and 0.05 p.p.m. respectively are not uncommon and the rate at which $\mathrm{SO}_{2}$ is oxidized to sulphate is about $3 \% \mathrm{~h}^{-1}$. Thus in polluted air, where significant amounts of $\mathrm{SO}_{2}$, olefin and ozone occur, the oxidation of $\mathrm{SO}_{2}$ by way of a shortlived intermediate of the olefin-ozone reaction may well be important.

\section{STRESS ANALYSIS}

\section{Progress with Lasers}

from a Correspondent

AN interesting meeting on holography and laser applications in the analysis of displacement and strain was held at the National Physical Laboratory on February 7. There were nine speakers representing between them the National Engineering Laboratory, the National Physical Laboratory, University College, Swansea, Loughborough University of Technology and the Atomic Weapons Research Establishment (AWRE). It was very clear that the strongest interests represented were those of optics, and that the analysis of strain measurement by these methods still has some way to go. The challenge of most of the work discussed is to make it positively useful in real circumstances, but there were few examples of actual measurements of strain. Of the real applications mentioned, an important subdivision could be drawn between those optical techniques which are an alternative to existing methods and those which enable additional information to be obtained. It is the latter type which is most likely to make an impact on technological developments.

Dr J. M. Burch (NPL) was at pains to point out that holographic interferometry was invented simultaneously by several

\title{
Salic Bias of Continental Crust
}

WHY is it that continental alkaline provinces contain a far higher proportion of salic rocks than do corresponding oceanic areas? For example, up to half the volume of lava in a continental province may comprise rhyolites, phonolites and trachytes, whereas an oceanic island contains very little salic material. Moreover, why is it that in continental provinces salic intrusions are most frequently of central form whereas mafic intrusions are most frequently of dyke form?

In next Monday's Nature Physical Science (March 19), Gill proposes a hypothesis which gives plausible answers to both of these questions and which overcomes the principal objection to existing explanations (partial melting and magma stratification) for the salic bias of continents, namely, that such explanations do not actually differentiate between continents and oceans. In other words, although partial melting and magma stratification could lead to the presence of salic material in the continental crust, there is no obvious reason why oceanic crust should be excluded from the action of such processes.

Gill's new hypothesis stems basically from the expected disparity in the time scales of crustal and mantle processes. The point here is that mafic dyking in alkaline provinces is clearly an intermittent process dependent upon crustal conditions, whereas there is no obvious reason why magma generation should cease just because and when crustal conditions are not appropriate to dyking. It is therefore logical to ask what happens to newly generated magma during periods of no dyking when access to the surface by way of fissures is not possible.

Density considerations suggest to Gill that when continental crust is not amenable to dyking, magma is at first restricted to depths greater than about $10 \mathrm{~km}$ where it cools, in time giving low-temperature residual liquids. Because of a relative lack of buoyancy, mafic components of the magma will be confined to this reservoir but the salic magma may rise by stoping and thus give upper crustal central forms. By contrast, oceanic crust offers much less restriction on dyking and so activity is predominantly basaltic. The critical difference between continental and oceanic crust, which leads to the salic bias of the former, is thus simply the different propensities to allow crustal extension. 